\title{
Vida útil em estrutura de concreto armado: estudo de caso em edificação de interesse histórico-cultural na região da serra gaúcha
}

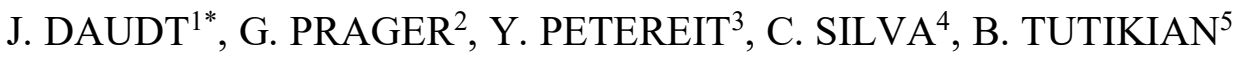 \\ *Autor de Contato: julio.daudt@gmail.com
}

${ }^{1}$ Engenheiro Civil, M.Sc., Universidade do Vale do Rio dos Sinos - Unisinos, São Leopoldo, Brasil.
2 Engenheiro Civil, M.Sc., Universidade do Vale do Rio dos Sinos - Unisinos, São Leopoldo, Brasil.
3 Engenheira Civil, M.Sc., Universidade do Vale do Rio dos Sinos - Unisinos, São Leopoldo, Brasil.
${ }^{4}$ Arquiteta e Urbanista, M.Sc., Universidade do Vale do Rio dos Sinos - Unisinos, São Leopoldo, Brasil.
${ }^{5}$ Engenheiro Civil, Sc.D., Professor, Universidade do Vale do Rio dos Sinos - Unisinos, São Leopoldo, Brasil.

\section{RESUMO}

Este artigo tem como objetivo determinar a perda de capacidade resistente de elementos de concreto armado e a vida útil remanescente de elementos estruturais em uma edificação de interesse histórico e cultural na região da serra gaúcha. Para atender ao objetivo, realizou-se inspeção preliminar e fotográfica, e, a partir da definição dos pontos de avaliação, mediram-se os diâmetros das barras de aço expostas, no caso da avaliação da perda de capacidade resistente, e a profundidade de carbonatação para os pontos de avaliação da vida útil remanescente. Os resultados indicam que a perda mínima de capacidade resistente para os pontos com armadura exposta é de $28 \%$, e projeção mínima de vida útil remanescente inexistente, atingindo até 171 anos.

Palavras-chave: durabilidade; corrosão; concreto armado; edificação tombada. 


\section{INTRODUÇÃO}

As estruturas de concreto armado são fundamentais para o desenvolvimento da infraestrutura urbana. As propriedades mecânicas e a versatilidade de aplicação desse material caracterizam, quase que integralmente, os aspectos positivos de sua utilização; além de ser economicamente viável na maioria dos casos (BERTOLINI et al., 2004; MEHTA; MONTEIRO, 2014; NEVILLE; BROOKS, 2010). A corrosão nas armaduras é uma das principais formas de deterioração dessas estruturas de concreto armado, esse fato faz com que grandes investimentos sejam despendidos anualmente no mundo inteiro para o controle, investigação e reparação dessas estruturas (BROOMFIELD, 2007).

Sabe-se que o concreto armado é um material compósito que, normalmente, apresenta boa proteção contra os mecanismos de corrosão do aço que o compõe (GJORV, 2014; MEHTA; MONTEIRO, 2014). Verifica-se que essa combinação pode ser durável porque o concreto gera uma proteção química e física ao aço, podendo minorar significantemente os problemas de corrosão (BENTUR; DIAMOND; BERKE, 1997).

Quando o concreto entra em contato com o aço, o processo de corrosão é interrompido e o material entra em um estado estacionário de energia, uma vez que um filme de proteção é formado na interface do concreto com o metal (BROOMFIELD, 2007; DAVIS, 2000). Esse filme de passivação, como é conhecido, se forma naturalmente no concreto porque a solução dos poros da pasta de cimento é alcalina, com um pH entre 12 e 14; isso em virtude da alta concentração de hidroxilas provenientes dos compostos $\mathrm{KOH}, \mathrm{NaOH}$ e $\mathrm{Ca}(\mathrm{OH})_{2}$ formados no processo de hidratação do cimento. Assim, entende-se que a circunstância estabelecida favorece termodinamicamente a ocorrência da proteção passiva, mantendo o metal isolado do meio que desencadeia o fenômeno da corrosão (JONES, 1996; MAYS, 2003; TUUTTI, 1982).

Para Bentur, Diamond e Berke (1997) e Broomfield (2007), a integridade da camada passiva - e a consequente resistência à corrosão - é afetada ao longo do tempo pelas reações do concreto com os agentes agressivos do meio externo. Dentre as reações prejudiciais, duas se destacam: a redução do $\mathrm{pH}$ em função da carbonatação, que é uma reação química do $\mathrm{CO}^{2}$ com os álcalis da solução dos poros; e a degradação do filme de passivação a partir da penetração de íons cloreto, que por difusão atravessam o cobrimento de concreto e atacam localmente o aço (CARINO, 1999; TUUTTI, 1982).

A carbonatação é um processo lento e ocorre da superfície para o interior. Nota-se que a taxa de carbonatação depende da permeabilidade do concreto, seu teor de umidade, teor de $\mathrm{CO}_{2}$ do ambiente de exposição e umidade relativa. A carbonatação reduz a natureza alcalina da pasta de cimento hidratada para um $\mathrm{pH}$ de aproximadamente 8 , condição em que o filme de passivação é desformado e os mecanismos de corrosão são iniciados na presença de $\mathrm{H}_{2} \mathrm{O}$ e $\mathrm{O}_{2}$. Neste contexto, caso toda a espessura de cobrimento de concreto da armadura seja carbonatada e houver presença de umidade e oxigênio, ocorrerá a corrosão do aço e, devido ao processo expansivo, fissuração da estrutura do material (BROOMFIELD, 2007; MEHTA; MONTEIRO, 2008; NEVILLE; BROOKS, 2010).

Nesse sentido, Aïtcin e Mindess (2011) e Richardson (2002) salientam a necessidade de se conhecer a durabilidade das estruturas de concreto armado e sua vida útil remanescente, visto que a degradação deste material gera um impacto socialmente contraproducente, economicamente insustentável e ambientalmente negativo. 
Segundo Helene (1993), entende-se por vida útil o período no qual a estrutura é capaz de desempenhar as funções para as quais foi projetada. Podendo-se distinguir pelo menos três situações:

a) Período que vai até a despassivação da armadura, normalmente denominada de período de iniciação. A esse período pode-se associar a chamada vida útil de projeto. Normalmente correspondente ao tempo necessário para que a frente de carbonatação ou a frente de cloretos atinjam a armadura;

b) Período que vai até o momento em que aparecem manchas na superfície do concreto, ou ocorrem fissuras no concreto de cobrimento, ou ainda quando há o destacamento do concreto de cobrimento. A esse tempo associa-se a chamada vida útil de serviço ou de utilização;

c) Período que vai até a ruptura e colapso parcial ou total da estrutura, a esse período associa-se a chamada vida útil total.

De acordo com Isaia (2004), perante os conceitos que englobam a durabilidade e vida útil das edificações, tem-se uma preocupação maior na determinação destes em edificações que são patrimônios históricos, a fim de elaborar planos de restauração e preservação adequados. Ainda segundo o autor, o conceito de preservação de edificações históricas no século XXI parte do princípio de que o patrimônio possui um valor, não apenas pelo passado como também pela história que terá pela frente. Considerando este significado, caracteriza-se que o patrimônio histórico possui "vida", ou seja, um valor intrínseco pelos acontecimentos que nele se desenrolará. Esta vida, do ponto de vista da deterioração dos materiais, pode ser considerada como a vida útil da edificação, isto é, período no qual a edificação permanece contribuindo em todos os aspectos para a sociedade em que está inserida. Barbosa (2010) afirma que para a preservação de edificações de interesse histórico cultural e elaboração de um plano de restauração adequado e realista é essencial conhecer a vida útil e o estado de deterioração da edificação.

A partir desta contextualização, é possível afirmar que se fazem importantes os estudos sobre as técnicas de diagnóstico e de determinação de vida útil remanescente para as edificações, e não somente para aquelas com interesse histórico-cultural. A definição do período em que a estrutura de determinada edificação irá se manter sob condições mínimas de serviço e utilização pode trazer relevantes parâmetros técnicos para a tomada de decisão sobre o desenvolvimento de um plano de manutenção e/ou recuperação.

Os modelos teóricos de previsão de vida útil são utilizados na comunidade técnico-científica principalmente na validação do tempo de vida útil remanescente das estruturas de concreto armado, e consistem em modelos matemáticos que tem o intuito de reproduzir os fenômenos naturais, físicos e químicos, quantificando sua ocorrência, baseando-se em uma ou mais características do concreto e do meio de exposição (PACHECO, 2016).

Entre os modelos de previsão de vida útil, destaca-se o modelo de Tuutti (1982), que considera os períodos de iniciação e propagação dos danos nas estruturas. Ramezanianpour, Ghahari e Esmaeili (2014) dizem que o tempo que a frente de carbonatação leva para atingir a armadura depende de muitos fatores, mas analisando holisticamente, diz-se que depende da espessura da camada de cobrimento e da taxa de difusão do dióxido de carbono $\left(\mathrm{CO}_{2}\right)$ no concreto. Smolczyk (1969) deu origem aos estudos matemáticos de previsão de vida útil, e mostra que comumente essa taxa de carbonatação no concreto pode ser descrita por meio da Equação 1: 


$$
\mathrm{d}=\mathrm{K} \cdot \mathrm{t}^{1 / \mathrm{n}}
$$

Equação 1

Em que "d" é a profundidade de carbonatação ( $\mathrm{mm}$ ) e "t $\mathrm{t}$ " é o tempo (anos). Muitas vezes o expoente "n" é 2, podendo ser considerado um fenômeno de tendência parabólica (TUUTI, 1982). O coeficiente de carbonatação " $\mathrm{K}$ " $\left(\mathrm{mm} / \mathrm{ano}^{1 / 2}\right)$ pode, portanto, ser considerado como uma medida da taxa de penetração da carbonatação para as respectivas condições ambientais e do concreto (SMOLCZYK, 1969).

Diante do exposto, para o prédio principal de uma edificação estruturada em concreto armado e de interesse histórico-cultural na região da serra gaúcha, este artigo tem como objetivo determinar a perda de capacidade resistente de elementos de concreto armado em que a vida útil de serviço já foi atingida e determinar a vida útil remanescente de elementos em que não foram registrados visualmente manifestações patológicas de corrosão.

\section{MÉTODO}

\subsection{Objeto de Estudo}

O objeto de estudo deste trabalho consiste no complexo de edificações do Campus 8 da Universidade de Caxias do Sul, o qual é composto por prédios de interesse histórico-cultural, executado em concreto armado e tombado como patrimônio histórico da cidade. A sua configuração original, Colégio Santa Francisca Xavier Cabrini, foi inaugurada em 1961, passou pelo uso de uma indústria metalúrgica e atualmente sedia o campus de Artes e Arquitetura da UCS (Universidade de Caxias do Sul). Em 2012 o complexo foi tombado pelo Patrimônio Histórico Municipal, sendo o $39^{\circ}$ bem tombado em Caxias do Sul - RS.

A edificação está localizada na região oeste do município de Caxias do Sul, serra do estado do Rio Grande do Sul. Segundo os dados meteorológicos do Instituto Nacional de Meteorologia (INMET) do Ministério da Agropecuária, Pecuária e Abastecimento da República Federativa do Brasil, a região apresenta temperatura mínima média anual de $12,9^{\circ} \mathrm{C}$, temperatura máxima média anual de $22,9^{\circ} \mathrm{C}$, precipitação média mensal de $145 \mathrm{~mm}$ e direção predominante dos ventos sudoeste-oeste (SSW).

A Figura 1 apresenta uma representação do ambiente de exposição da edificação, indicando a direção predominante dos ventos, a área verde existente à noroeste da edificação e a área urbana e industrial à sul e leste da edificação. Além disso, aproximadamente a $400 \mathrm{~m}$ ao sul da edificação é existente a rodovia Rota do Sol (RS-122), caracterizada por tráfego de veículos de passeio e caminhões de transporte rodoviário. 
Figura 1: localização do Campus 8 da UCS.

(a) e (b) Representação do ambiente de exposição da edificação, da fachada de estudo (fachada sul). (c) e (d) Direção predominante dos ventos (SSW).
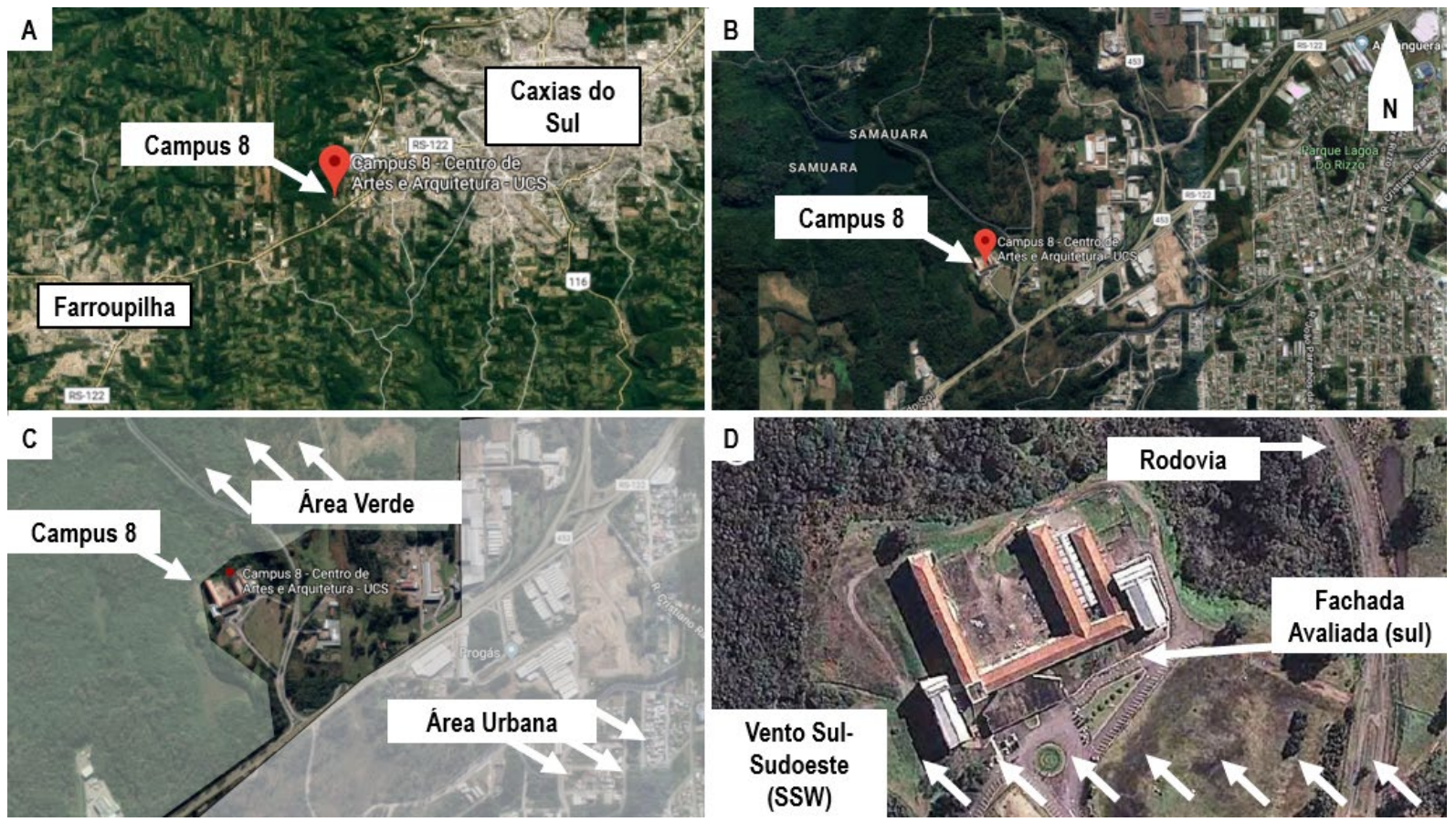

Fonte: Google Maps (2018). Adaptado pelos autores.

Identifica-se, a partir da direção predominante dos ventos e da caracterização do entorno da edificação, a qual contêm uma área verde na região noroeste e área urbana frontal à fachada sul, que existe uma tendência representativa de que a fachada sul do prédio principal esteja exposta à maior nível de agressividade do meio de exposição, haja vista que é provável que os agentes agressivos sejam carreados pelo vento em direção à fachada. Esta hipótese é corroborada por autores como Ekolu (2016), que indicam que na direção predominante dos ventos os elementos estruturais recebem maior incidência de exposição aos agentes agressivos do meio. Segundo a NBR 6118 (ABNT, 2014), a edificação insere-se em uma zona de agressividade II (moderada), sendo, neste caso, $\mathrm{o}_{2} \mathrm{O}$ elemento mais agressivo, que potencialmente desencadeia os processos de deterioração da estrutura de concreto armado.

Para atingir de maneira mais otimizada o objetivo proposto neste trabalho, propôs-se estudar o prédio principal da edificação, conforme caracterização demonstrada na Figura 2.

Figura 2: fotografia da edificação em vista frontal para identificação da fachada estudada.

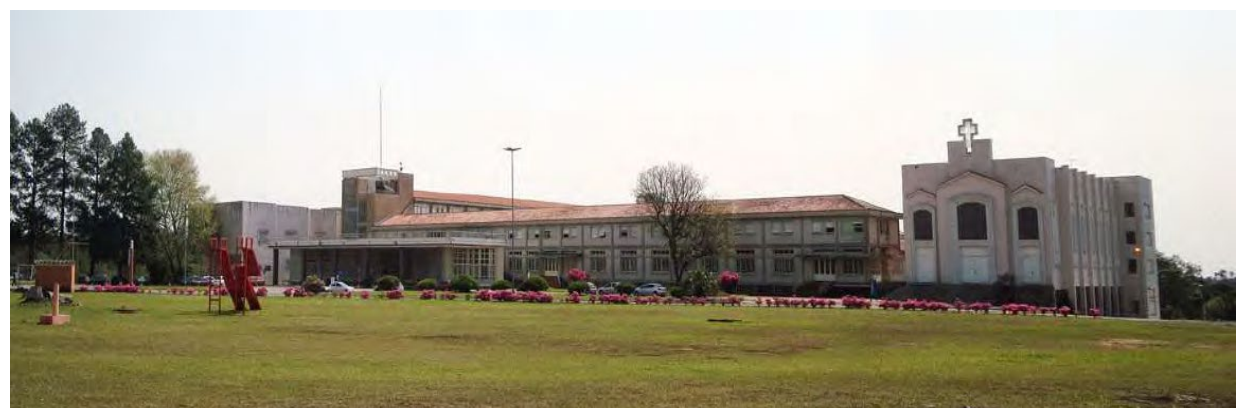

Fonte: Pessato (2012). 
Além disso, a fim de setorizar a avaliação, acumularam-se os pontos de estudo na fachada sul (fachada frontal da edificação), conforme pode ser visualizado na Figura 3; em que existe uma tendência de que os elementos estruturais estejam mais deteriorados, conforme discutido em função das condicionantes físicas de exposição e a partir de uma avaliação prévia visual efetuada no dia do levantamento de dados.

Figura 3: (A) Setorização da edificação e (B) localização dos pontos de estudo.

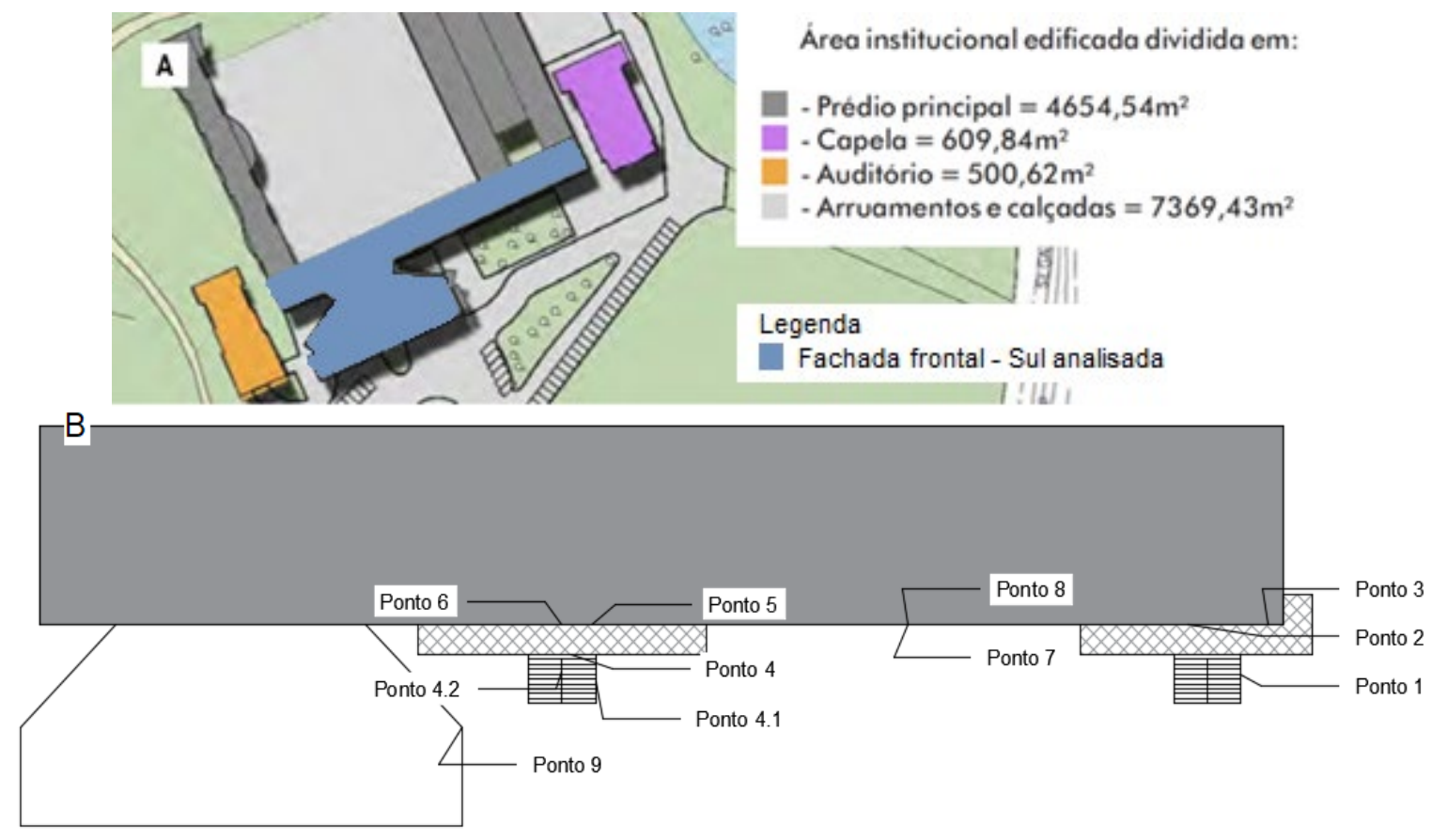

Fonte: (A) Pessato (2012); (B) Elaborado pelos autores.

Nos pontos identificados 1 (viga da escada), 4.1 (viga da escada), 4.2 (degrau da escada) e 9 (pilar de borda), registraram-se os diâmetros das barras expostas, visto que nestes pontos o nível de deterioração da estrutura é elevado, apresentando destacamento do concreto de cobrimento e acúmulo de produtos de corrosão na superfície do metal já exposto. Salienta-se também que os elementos avaliados se situam nas escadas de acesso ao prédio principal, que estão interditadas ao público. Dentro deste contexto, definiram-se como pontos críticos de diagnóstico os pontos supracitados.

Para os pontos subsequentes, a análise foi realizada a partir de uma inspeção detalhada por meio do diagnóstico da condição de carbonatação da espessura de cobrimento de concreto e do revestimento, tipo e espessura. Foram escolhidos a partir da proximidade com as escadas de acesso que estão em estado crítico de deterioração, com o intuito de restringir a inspeção. Se avaliou também um pilar central da fachada, ponto 7, para maior representatividade do estudo, em que o ponto se caracteriza por uma averiguação no ambiente interno da edificação.

\subsection{Procedimento de Estudo}

O estudo foi realizado a partir da definição e setorização da edificação avaliada, em que se definiram os pontos a serem diagnosticados detalhadamente como sendo aqueles de maior 
incidência de exposição aos agentes agressivos carreados pelo vento e gerados pela zona urbana e industrial do entorno.

Os pontos de avaliação de perda mínima de capacidade resistente (Figura 4 "a" e "b") foram limpos mecanicamente com escova de aço, marreta e talhadeira e as armaduras expostas tiveram o diâmetro medido com paquímetro. Chama-se de perda mínima de capacidade resistente porque a definição do diâmetro inicial das barras ( $\varphi$ de construção) foi estimado como a medida tabelada comercialmente e imediatamente superior àquela registrada na inspeção. Isso foi necessário para a validação do estudo em função da inexistência de registros documentados de projeto e/ou as built da construção em que o diâmetro das barras estivesse identificado. Destaca-se aqui, que com a adoção deste procedimento para determinação da perda de resistência dos elementos avaliados infere-se incerteza nos resultados obtidos. Entretanto, como dados de verificação da perda mínima de seção, os resultados podem ser discutidos e analisados qualitativamente.

Para definição da vida útil remanescente, nos pontos de análise foram identificados os posicionamentos das barras de armadura por meio da técnica de pacometria com o equipamento de identificação eletromagnética de barras. Depois disso, com furadeira e broca de $8 \mathrm{~mm}$ se realizaram furos com profundidade progressiva (intervalos de $5 \mathrm{em} 5 \mathrm{~mm}$ ) e coletou-se o pó do material perfurado para verificação do $\mathrm{pH}$, e por consequência, da condição de carbonatação do cobrimento de concreto (Figura 4 "c" e "d").

Figura 4: diferença de condições dos grupos de pontos avaliados. (a) e (b) - determinação da perda de capacidade resistente. (c) e (d) - determinação da vida útil remanescente.

(a)

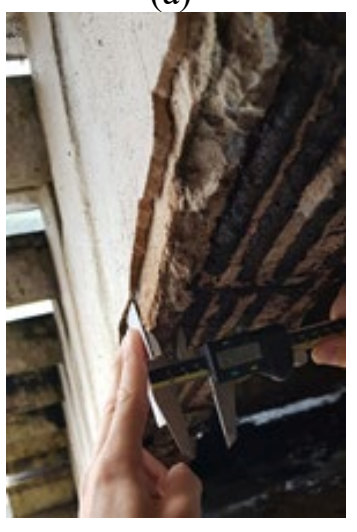

(b)

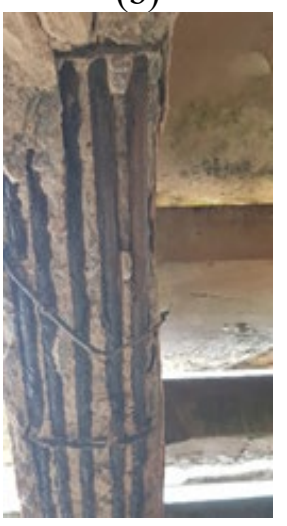

(c)

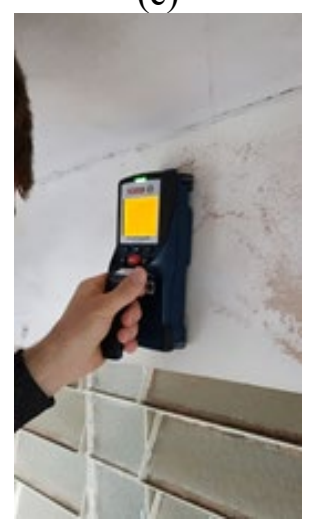

(d)

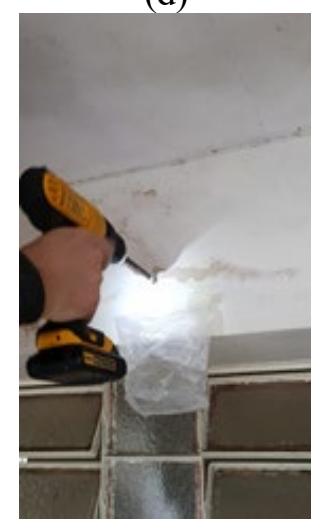

Fonte: registrado pelos autores.

O cálculo de vida útil remanescente foi realizado com base no modelo de previsão de vida útil de Tuuti (1982).

Não se considerou no cálculo a carbonatação do revestimento de argamassa, visto que conforme Mehta e Monteiro (2014) os coeficientes " $\mathrm{K}$ " de carbonatação dos materiais argamassa e concreto são significativamente diferentes entre si, ainda que o meio de exposição seja o mesmo.

\subsection{Medição da profundidade da carbonatação}

A determinação da profundidade de carbonatação foi realizada por meio de um indicador químico de $\mathrm{pH}$, visto que é a técnica mais difundida, devido a sua praticidade e baixo custo (PAULETTI, 2004). 
As diretrizes desse ensaio atenderam a prescrição francesa RILEM CPC-18 (1988). Utilizou-se a solução de fenolftaleína (1 g de fenolftaleína +49 g de álcool +50 g de água), sendo esta de tonalidade rosada em contato com os álcalis do concreto ( $\mathrm{pH}$ acima de 9), e tornando-se transparente quando em contato com superfície de $\mathrm{pH}$ inferior a 9 (superfície carbonatada).

Com o pó proveniente do furo realizado de $5 \mathrm{em} 5 \mathrm{~mm}$, determinou-se a profundidade (com $5 \mathrm{~mm}$ de precisão) em que o pó coletado apresentou coloração rosada, demonstrando o ponto de viragem de $\mathrm{pH}$, e, por consequência, a espessura da frente de carbonatação.

\section{APRESENTAÇÃO E DISCUSSÃO DOS RESULTADOS}

Os pontos avaliados mostraram-se variados quanto ao nível de criticidade das manifestações patológicas identificadas e de profundidades de carbonatação medidas.

Esta variação de nível de deterioração pode estar associada à existência ou não de revestimento de argamassa e camada de pintura acrílica nos elementos estruturais considerados, haja vista que nos pontos que indicam perda de capacidade resistente pela ação do fenômeno de corrosão não foi identificada camada de revestimento com pintura. Já para os pontos com menor nível de deterioração, todos apresentaram camadas de revestimento de argamassa e ao menos uma camada de tinta acrílica ou revestimento com pastilhas. Observa-se também que os elementos mais atingidos estão expostos diretamente a incidência de ciclos de chuva e sol, o que contribui para a deterioração da estrutura.

\subsection{Vida Útil Remanescente}

Para os pontos de análise de vida útil remanescente, em que se aplicou o modelo de previsão de vida útil de Tuuti (1982), a Tabela 1 mostra os resultados obtidos. Observa-se que os valores práticos que podem ser avaliados são os dos pontos 6 e 7, em que a vida útil remanescente é de 171 anos e 71 anos, respectivamente. Os outros valores configuram-se fora de um espectro prático de estudo, atingindo 5650 anos de vida útil remanescente, no caso do ponto 3, em que o revestimento com pastilhas provavelmente inibiu a penetração dos gases agressivos e, portanto, a ocorrência dos mecanismos de carbonatação.

Tabela 1: análise de vida útil remanescente.

\begin{tabular}{cccccc}
\hline Ponto de Estudo & $\begin{array}{c}\text { Tipo de } \\
\text { Revestimento }\end{array}$ & $\begin{array}{c}\text { Cobrimento da } \\
\text { Armadura }\end{array}$ & $\begin{array}{c}\text { Frente de } \\
\text { Carbonatação }\end{array}$ & $\mathrm{K}\left(\mathrm{mm} / \text { ano }^{1 / 2}\right)^{*}$ & $\begin{array}{c}\text { Vida Útil } \\
\text { Remanescente }\end{array}$ \\
\hline 2 & ARG & $10 \mathrm{~mm}$ & $10 \mathrm{~mm}$ & $-1,32$ & ZERO \\
3 & PAS & $10 \mathrm{~mm}$ & $1 \mathrm{~mm}$ & 0,1324 & 5650 anos \\
5 & ARG & $30 \mathrm{~mm}$ & $30 \mathrm{~mm}$ & $-3,97$ & ZERO \\
6 & PAS & $10 \mathrm{~mm}$ & $5 \mathrm{~mm}$ & 0,6623 & 171 anos \\
7 & PAS & $15 \mathrm{~mm}$ & $10 \mathrm{~mm}$ & 1,3245 & 71 anos \\
8 & ARG & $10 \mathrm{~mm}$ & $2 \mathrm{~mm}$ & 0,2649 & 1370 anos \\
\hline
\end{tabular}

Legenda: ARG - argamassa; PAS - pastilha cerâmica; *K - coeficiente de carbonatação (ver Equação 1).

Fonte: elaborado pelos autores.

Nota-se que nos casos dos pontos 5 e 7, o cobrimento de concreto para a armadura é de 3,0 e 1,5 $\mathrm{cm}$ de espessura, respectivamente. Isso pode ser justificado, provavelmente, por variações construtivas. Salienta-se, também, que na época de construção (década de 50) a norma técnica 
vigente era a NR-1 (ABNT, 1949), que exigia um mínimo de 1,5 cm para elementos estruturais no interior da edificação e 2,0 cm quando expostos ao ambiente externo; evidenciando que os elementos estruturais estudados não atendem a legislação da época.

Para os pontos 2 e 5 a vida útil já foi atingida, visto que a profundidade de carbonatação está na superfície da armadura, o que evidencia o princípio dos mecanismos de corrosão que potencialmente afetarão estes elementos estruturais. Isso muito provavelmente está associado ao tipo de revestimento do elemento e do nível de exposição ao meio, que nestes casos caracterizavamse somente por uma camada de argamassa em um ambiente externo da edificação. Nota-se a diferença em relação ao ponto 8 com revestimento de argamassa, porém com exposição interna, que ainda se mantem protegido por 1370 anos, aproximadamente.

Identifica-se também a influência do revestimento em pastilhas cerâmicas no desempenho dos elementos frente aos mecanismos de deterioração. Os pontos 3, 6 e 7 apresentam vida útil remanescente de 5650, 171 e 71 anos, respectivamente, mostrando que o uso da edificação em nada fica comprometido pela segurança estrutural destes elementos em que os pontos de estudo se inserem. É possível crer que o revestimento em pastilhas protege o concreto estrutural do fenômeno de carbonatação, e, por consequência, a armadura dos mecanismos de corrosão atuantes.

Dos pontos verificados na análise de vida útil remanescente, discute-se que a viga de borda em que os pontos 2 e 5 foram alocados neste estudo (Figura 3 "b") necessita de interferência construtiva, a fim de garantir a manutenção do elemento estrutural.

\subsection{Perda de Capacidade Resistente}

Os elementos que apresentaram estado de corrosão visível não são passíveis de avaliação quanto à vida útil remanescente, mas é possível realizar uma avaliação quantoà capacidade resistente do elemento. Percebe-se, a partir da Figura 5, que os elementos considerados nesta etapa do estudo apresentam uma condição crítica de segurança estrutural, tendo em vista o contexto de corrosão identificado. A Figura 5 "a" refere-se ao ponto 1, Figura 5 "b" ao ponto 4.1, Figura 5 "c" ao ponto 4.2 e Figura 5 "d" ao ponto 9 do estudo.

Figura 5: estado de deterioração dos elementos avaliados.

(a)

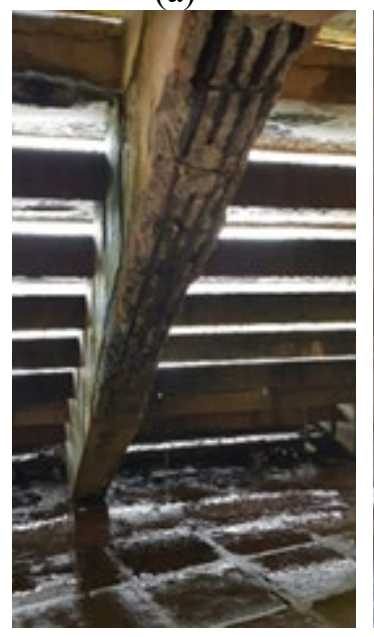

(b)

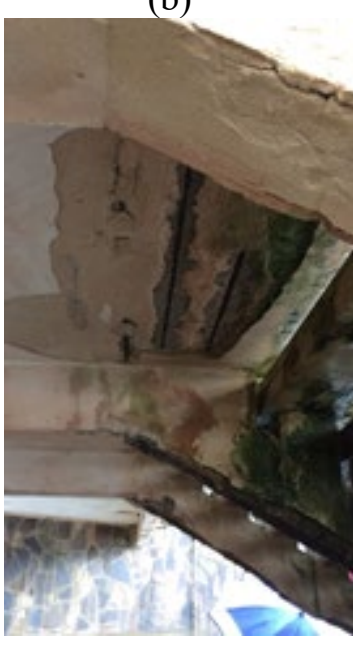

(c)

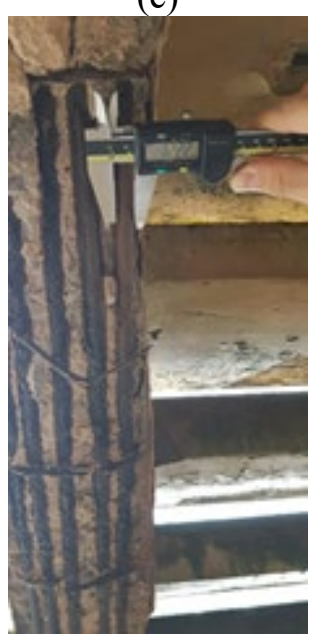

(d)

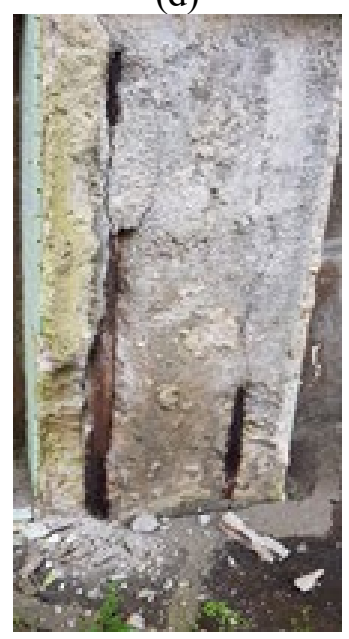

Fonte: registrado pelos autores. 
A Tabela 2 apresenta os resultados para estes pontos, considerando o provável diâmetro inicial da barra avaliada, conforme já exposto no item 2.2.

Tabela 2: perda de capacidade resistente (considerando a provável dimensão da barra de construção).

\begin{tabular}{cccccc}
\hline Ponto Estudado & Cobrimento & $\begin{array}{c}\text { Frente de } \\
\text { Carbonatação }\end{array}$ & $\begin{array}{c}\varnothing \text { Armadura } \\
\text { Medido }\end{array}$ & $\begin{array}{c}\text { Ø Armadura Inicial } \\
\text { Mínima Estimada }\end{array}$ & $\begin{array}{c}\text { Perda Mínima de } \\
\text { Capacidade } \\
\text { Resistente }\end{array}$ \\
\hline 1 & $24 \mathrm{~mm}$ & $24 \mathrm{~mm}$ & $12,2 \mathrm{~mm}$ & $16 \mathrm{~mm}$ & $24 \%$ \\
4.1 & $20 \mathrm{~mm}$ & $20 \mathrm{~mm}$ & $15 \mathrm{~mm}$ & $16 \mathrm{~mm}$ & $7 \%$ \\
4.2 & $23 \mathrm{~mm}$ & $23 \mathrm{~mm}$ & $9 \mathrm{~mm}$ & $12,5 \mathrm{~mm}$ & $28 \%$ \\
9 & $20 \mathrm{~mm}$ & $20 \mathrm{~mm}$ & $17 \mathrm{~mm}$ & $20 \mathrm{~mm}$ & $15 \%$ \\
\hline
\end{tabular}

Fonte: elaborado pelos autores.

Vê-se que as vigas de sustentação dos degraus das escadas de acesso estão comprometidas (Figura 5 "a", "b" e "c"), sendo que as barras longitudinais chegam a 28\% de perda mínima de área de seção transversal da armadura principal, no caso do ponto 4.2.

O ponto 9 é aquele em que a análise da perda de seção foi realizada no pilar de borda, normalmente identificado como um elemento que representa significativa importância na estabilidade global da edificação. Apresenta uma perda mínima de área de seção de 15\%, mostrando a necessidade de reparo estrutural neste ponto e seus similares.

A deterioração das barras metálicas de construção, por meio dos mecanismos de corrosão, deve estar relacionada ao ambiente externo de exposição da edificação e aos ciclos térmicos e de molhagem e secagem que a fachada avaliada coloca-se, sendo isso associado a falta de proteção (revestimento) adequada.

Em todos os pontos é verificado algum nível de perda de capacidade resistente, variando de 7\% a $28 \%$ no caso mais grave. Entretanto, vê-se que a minoração de projeto da capacidade resistente dos elementos, considerada nos coeficientes de segurança, ainda se mostra efetiva, visto que as escadas de acesso se mantêm estáveis. Isso não quer dizer que a manutenção é dispensável, sendo fundamental a operacionalização de reparos estruturais nestes elementos.

\subsection{Proposta Simplificada de Recuperação}

O nível e precisão da recuperação das estruturas de concreto, está atrelado ao diagnóstico e exame conciso dos motivos que fizeram a estrutura atingir tal condição, assim como seu nível de degradação. Após essa etapa preliminar é realizado a escolha da técnica construtiva, sendo que neste caso foram utilizados as mais usuais. Levando em consideração o nível de segurança a ser restabelecido, gastos com manutenção futura dos elementos e estado de deterioração são estabelecidos dois níveis de intervenção, sendo eles a recuperação da camada de cobrimento, aplicado aos elementos que possuem seu revestimento e parte do concreto carbonatado e reconstrução por completo das escadas de acesso.

As escadas (Figura 5 "a", "b" e “c”), devido ao seu processo de corrosão generalizada e alto nível de complexidade para realizar o reestabelecimento da vida útil, optou pela reconstrução por 
completo da estrutura respeitando fielmente o projeto inicial, visto que se trata de uma edificação tombada.

O pilar constatado com armadura aparente (Ponto 9), optou por realizar reparo superficial do concreto, promovendo a remoção completa de todo concreto trincado e/ou carbonatado, até o encontro da armadura. Após, a limpeza da armadura com jateamento de ar comprimido e remoção do restante de aço corroído com escova de aço. E para a realização do fechamento, procede-se com o lançamento do graute em formas periféricas ao pilar, promovendo uma nova camada de cobrimento das armaduras.

Os elementos restantes que perderam a sua vida útil, devido à frente de carbonatação, sugere-se remover o revestimento de argamassa e o cobrimento do concreto e reestabelecer nova camada de cobrimento para inibir o processo de corrosão das armaduras.

\section{CONSIDERAÇÕES FINAIS}

A investigação da previsão da vida útil de estruturas de concreto armado é de vital importância para a preservação de edificações e elaboração de um plano de manutenção e/ou recuperação adequado, principalmente em casos de edificações de interesse histórico cultural.

Diante da análise da edificação de interesse histórico-cultural na região da serra gaúcha, foi possível constatar o nível de degradação das estruturas da fachada frontal sul, a mais exposta aos agentes externos, devido às condições climáticas do local, com precipitação média mensal de 145 mm e direção predominante dos ventos sudoeste-oeste, conciliada com a ação da zona urbana e vias de tráfego urbano da região.

Por conseguinte, é possível observar que alguns elementos da fachada de estudo, a exemplo das escadas de acesso estão praticamente comprometidas a nível de intervenção, com perda de capacidade resistente de até $28 \%$. As vigas adjacentes às escadas e os elementos que apresentam frente de carbonatação a nível de armadura, estes em condições menos expostas, são passiveis de recuperação da camada de cobrimento. Os elementos externos que ainda possuem vida útil remanescente, estes menos degradados, é compreendido devido a existência de revestimento de argamassa e pastilhas cerâmicas, com a condição do avanço da frente de carbonatação similar dos elementos internos da edificação.

Por fim, por se tratar de uma edificação tombada como patrimônio histórico da cidade e ser utilizada como ambiente de ensino faz-se necessário a prática do plano de recuperação das estruturas de concreto, de modo à manter a integridade e funcionalidade da edificação. 


\section{REFERÊNCIAS}

Aïtcin, P. C.; Mindess, S. (2011). “Sustainability of Concrete”. 1 ed. Spon Press, New York.

Associação Brasileira de Normas Técnicas. (1949) NR-1: Estruturas de concreto. Rio de Janeiro.

Associação Brasileira de Normas Técnicas. (2014). NBR 6118: Projeto de estruturas de concreto - procedimento. Rio de Janeiro.

Barbosa, M.T.G.; Polisseni, A.E.; Tavares, F.M. (2010). "Patologias de edifícios históricos tombados". in: Anais do $1^{\circ}$ Encontro Nacional da Associação de Pesquisa e Pós-Graduação Em Arquitetura e Urbanismo (ENANPARQ). Rio de Janeiro, 1-13.

Bentur, A.; Diamond, S.; Berke, N. S. (1997). "Steel Corrosion in Concrete: Fundamentals and Civil Engineering Practice". 1 ed. E \& FN Spon, London.

Bertolini, L.; Elsener, B.; Pedeferri, P.; Polder, R. B. (2004). "Corrosion of Steel in Concrete: Prevention, Diagnosis, Repair". 1 ed. Wiley-VCH Verlag GmbH \& Co. KGaA, Weinheim.

Broomfield, J. P. (2007). “Corrosion on Steeel in Concrete”. 1 ed. E. \& Fn Spon, London.

Carino, N. J. (1999). Nondestructive Techniques to Investigate Corrosion Status in Concrete Structures. Journal of Performance of Constructed Facilities. 13: 96-106.

Davis, J. R. (2000). “Corrosion: Understanding the Basics”. 1 ed. ASM International, Ohio.

Ekolu, S. O. (2016). A review on effects of curing, sheltering, and CO2 concentration upon natural carbonation of concrete. Construction and Building Materials. 127: 306-320.

Gjorv, O. E. (2014). “Durability Design of Concrete Structures in Severe Environments”. 2 ed. Crc Press, Boca Raton.

Helene, P.R.L. (1993). "Contribuição ao estudo da corrosão em armaduras de concreto armado", Tese de Doutorado, Universidade de São Paulo.

Isaia, G.A. (2004). "Conceitos de modernização de edificações históricas: um legado do século XX”, Especialização em conservação e restauração do património cultural, Universidade Federal de Santa Maria.

Jones, D. A. (1996). "Principles and Prevention of Corrosion". 2 ed. Prentice Hall, New Jersey.

Mays, G. C. (2003). "The behaviour of concrete". in: Mays, G. C. "Durability of Concrete Structures: Investigation, repair, protection". 1 ed. E \& FN Spon, London.

Mehta, P. K.; Monteiro, P. J. M. (2014). “Concreto: Microestrutura, Propriedades e Materiais". 2 ed. IBRACON, São Paulo.

Neville, A. M.; Brooks, J. J. (2010). “Concrete Technology”. 2 ed. Pearson Education, Harlow. 
Pacheco, F. (2016). "Investigação da relação entre os parâmetros de projeto das estruturas de concreto armado visando à durabilidade". Dissertação de Mestrado, Universidade do Vale do Rio dos Sinos (Unisinos).

Pauletti, C. (2004). "Análise Comparativa de Procedimentos para Ensaios Acelerados de Carbonatação”. Dissertação de Mestrado, Universidade Federal do Rio Grande do Sul.

Pessato, L.(2012). "Cidade das Artes: requalificação do Campus 8 da UCS". Trabalho de Conclusão de Curso (Graduação em Arquitetura e Urbanismo), Universidade Federal do Rio Grande do Sul. Porto Alegre.

Ramezanianpour, A. A.; Ghahari, S. A.; Esmaeili, M. (2014). Effect of combined carbonation and chloride ion ingress by an accelerated test method on microscopic and mechanical properties of concrete. "Construction and Building Materials". 58: 138-146.

Richardson, M. G. (2002). "Fundamentals of Durable Reinforced Concrete". 1 ed. Spon Press, London.

RILEM, Recommandations. (1988). CPC-18: Measurement of hardened concrete carbonation depth. Mater Struct, 21: 453-455.

Smolczyk, H. G. (1969). "Discussion of principal paper of carbonation of concrete by Hamada". in: Proceedings of International Symposium on the Chemistry of Cement. Tokyo, p. 369-384.

Tuutti, K. (1982). "Corrosion of Steel in Concrete". Cement and Concrete Research Institute of Stockholm. 